\title{
Whole Body Vibration Exercises on Physiological and Hemodynamic Parameters of Spinal Cord Injury Individuals: A Systematic Review
}

Laisa Liane Paineiras-Domingos ${ }^{1,2,3 *}$, Danúbia da Cunha de Sá-Caputo ${ }^{1,2,3}$, Eliane O Guedes-Aguiar ${ }^{2,3,4}$, Eloá Moreira-Marconi², Marcia Cristina Moura-Fernandes ${ }^{2,5}$, Aline Silva Reis ${ }^{2,6}$, Pedro J Marín ${ }^{7}$, Christina Stark ${ }^{8}$, Marianne Unger ${ }^{8}$ and Mario Bernardo-Filho ${ }^{2}$

${ }^{1}$ Postgraduate Program in Medical Sciences, Rio de Janeiro State University, Rio de Janeiro, RJ, Brazil

${ }^{2}$ Department of Biophysics and Biometrics, Laboratory of Mechanical Vibrations and Integrative Practices, Institute of Biology Roberto Alcântara Gomes, Rio de Janeiro State University, Rio de Janeiro, RJ, Brazil

${ }^{3}$ Faculdade Bezerra de Araújo, Rio de Janeiro, RJ, Brazi

${ }^{4}$ Postgraduate Program in Health Sciences, Federal University of Rio Grande do Norte, Natal, RN, Brazil

${ }^{5}$ Postgraduate Program in Clinical and Experimental Physiopathology, University of the State of Rio de Janeiro, Rio de Janeiro, RJ, Brazil ${ }^{6}$ Professional Master's in Health, Laboratory Medicine and Forensic Technology, Roberto Alcântara Gomes Biology Institute, Rio de Janeiro State University, Rio de
Janeiro, RJ, Brazil

${ }^{7}$ CyMO Research Institute, Valladolid, Spain

${ }^{8}$ University of Cologne, Children's and Adolescent's Hospital, Cologne, Germany

\section{Abstract}

Background: Spinal cord injury ( $\mathrm{SCl})$ is a devastating clinical disorder that results in permanent and undesirable neurologic deficit. Exercises could bring benefits as the whole body vibration (WBV) exercises.

Objective: The aim of this review is describe the effects of the WBV exercises on physiological and hemodynamic parameters of SCl individuals.

Methods: Searches in PubMed and PEDRo databases with specific keywords were performed. Fifteen studies met the inclusion criteria to be evaluated and the level of evidence and the methodological quality (PEDRo scale) were determined.

Results: Although many variations of the WBV exercise protocols, responses were found on physiological and hemodynamic parameters.

Conclusion: Previous studies suggest that the WBV exercise can be a possible tool to be incorporated in rehabilitation programs of the $\mathrm{SCl}$ individuals.

Keywords: Whole body vibration exercises; Physical activity; Spinal cord injury; Muscle activity, Spasticity

\section{Introduction}

Spinal cord injury (SCI) is a devastating event often resulting in permanent neurologic deficit $[1,2]$. A spinal cord lesion may be suspected when there are bilateral motor and sensory signs or symptoms that do not involve the head or face. Motor deficits are manifested by weakness related to the involvement of the long fiber tracts in the spinal cord [3-5]. Other so-called segmental signs include lower motor neuron findings (atrophy, flaccid weakness, loss of reflexes) in a myotomal distribution at the specific level of involvement $[5,6]$.

SCI occurs through various countries throughout the world with an annual incidence of 15 to 40 cases per million [7]. Despite to the advances made in the understanding of the pathogenesis and improvements in early recognition and treatment, it remains an undesirable clinical condition, often producing severe and permanent disability [8].

Non traumatic and traumatic SCI can be observed [9-11]. Several diseases have a predilection for targeting specific areas or tracts within the spinal cord [12] and consequently, they can lead to the appearance of non-traumatic SCI. With a peak incidence in young adults, traumatic spinal cord injury (TSCI) remains a costly problem for society; direct medical expenses accrued over the lifetime of one patient range from 500,000 to 2 million US dollars [7]. The incidence in USA is higher than in most other countries. The main causes of TSCI in the United States are: motor vehicle accidents (48\%); falls (16\%); violence, especially gunshot wounds (12\%); sports accidents (10\%) and other (14\%) [13].

Individuals with TSCI often have associated brain and systemic injuries (e.g., hemothorax, extremity fractures, and intra-abdominal injury) that may limit the patient's ability to report localized pain [14].
Moreover, Deitrick and coauthors [15] have reported skin breakdown lesions of the legs in SCI patient. This fact would be associated with deficient sensitivity and immobility of the limbs, which result in areas subjected to prolonged pressures and poor circulation, with blood flow reduction.

It has been suggested that small vessel circulation is decreased in SCI. These also complicate the initial evaluation and management of patients with TSCI, and affect prognosis. About half of the TSCIs involves the cervical cord and as a result present quadriparesis or quadriplegia $[16,17]$. The severity of cord syndromes is classified using the American Spinal Injury Association (ASIA) Scale [18].

The ASIA Impairment Scale (AIS) is a clinician-administered scale used to classify the severity (completeness) of injury in individuals with SCI, based on the Frankel scale $[19,20]$. It identifies sensory and motor levels indicative of the highest spinal level demonstrating "unimpaired" function. Preservation of function in the sacral segments (S4-S5) is a key for determining the AIS grade $[19,20]$.

*Corresponding author: Laisa Liane Paineiras Domingos, Department of Biophysics and Biometrics, Institute of Biology Roberto Alcântara Gomes, Rio de Janeiro State University, Brazil, Tel: +55-21-28688332, Email: laisanit@gmail.com

Received November 12, 2018; Accepted November 27, 2018; Published November 30, 2018

Citation: Paineiras-Domingos LL, Sá-Caputo DC, Guedes-Aguiar EO, MoreiraMarconi E, Moura-Fernandes MC, et al. (2018) Whole Body Vibration Exercises on Physiological and Hemodynamic Parameters of Spinal Cord Injury Individuals: A Systematic Review. J Spine 7: 426. doi: 10.4172/2165-7939.1000426

Copyright: (c) 2018 Paineiras-Domingos LL, et al. This is an open-access article distributed under the terms of the Creative Commons Attribution License, which permits unrestricted use, distribution, and reproduction in any medium, provided the original author and source are credited. 
Citation: Paineiras-Domingos LL, Sá-Caputo DC, Guedes-Aguiar EO, Moreira-Marconi E, Moura-Fernandes MC, et al. (2018) Whole Body Vibration Exercises on Physiological and Hemodynamic Parameters of Spinal Cord Injury Individuals: A Systematic Review. J Spine 7: 426. doi: 10.4172/2165-7939.1000426

Page 2 of 1

In general, many authors have been concerned with investigating the motor and sensory dysfunctions of these individuals with SCI and the compromises resulting from these dysfunctions. However, this review seeks to investigate, besides musculoskeletal disorders, the possible hemodynamic complications that arose after the injury. Cardiovascular disturbances after SCI, such as blood pressure (BP) instability [21] and this hemodynamic compromise should be strongly countered by some type of intervention that involves the rescue of the motor and sensory functions of these individuals, like the exercises.

Considering the exercises as a modality of procedure of the physiotherapy to be used in the management of patients with SCI, Basso and Hansen [8] reported that exercises elicit both beneficial and deleterious biophysical effects after SCI. Moreover, they described that modulating the type, intensity, complexity, and timing of training it is possible to minimize risk and induce greater recovery. Nevertheless, Bizzarini and coauthors [22] report that an exercise program for people with SCI in the subacute phase might consider the inability in responding to the training program (bedrest syndrome). This would be related to the heart, lung, and muscles above the lesion would be not conditioned to exercise. Whole body vibration (WBV) exercise, as a modality of exercise has been used to manage the SCI individuals $[11,23,24]$

WBV exercise is generated when a subject is exposed to mechanical vibrations produced in oscillating/vibratory platforms (OVP) [25]. The mechanical vibration produced in an OVP is a physical agent with an oscillatory, sinusoidal and deterministic motion about an equilibrium point [26]. Frequency (f), amplitude (A), peak-to-peak displacement (D) and peak acceleration (aPeak) are biomechanical parameters that can be used to characterize the mechanical vibration. The peak acceleration of the mechanical vibration is calculated by the formula [25-27]:

$$
\left(\text { aPeak }=2 \times \pi^{2} \times f^{2} \times D\right)
$$

Other parameters must be also considered in the protocols related to the WBV exercise, such as the type of the platform, duration of the bout (working time), rest time between bouts, periodicity of the sessions or even the position adopted by the subject in the base of the OVP [26].

Cochrane [27] considers WBV exercise as a potential safe modality of physical activity in sport [28] fitness and health sectors. Patients with neurodegenerative disease [29], with stroke [30], with cerebral palsy [31], with multiple sclerosis [32], with osteogenesis imperfect [33], with Duchenne muscular dystrophy [34] and with SCI [24,35,36] have had clinical improvements with protocols involving WBV exercise. It is reported that strength [31] and power muscle [35] are increased after WBV exercise in individuals with diseases.

Regarding the involvement of WBV exercises in individuals with SCI, circulatory, functional and neuro-musculoskeletal effects have already been described [23,35,37-40]. Considering that this kind of exercise could be suggested as an effective strategy to manage SCI individuals, the aim of the current study is to review the effects and the feasibility of WBV exercise in these clinical conditions.

\section{Literature Review}

This study conforms to all Preferred Reporting Items for Systematic Reviews and Meta-Analyses (PRISMA) guidelines and reports the required information.

\section{Search strategy used to find the publications involving WBV and SCI}

Three reviewers independently accessed the bibliographical PubMed and PEDro databases on January $28^{\text {th }} 2017$ with the keywords

- Spinal cord injury

- Whole body vibration

- Spinal cord injury and physiotherapy

- Spinal cord injury and exercise

- Spinal cord injury and whole body vibration.

The number of publications (NP) was determined to each item searched in the two databases. About the databases used, briefly, PubMed comprises more than 25 million citations for biomedical literature from MEDLINE, life science journals and online book (http://www. ncbi.nlm.nih.gov/pubmed) and PEDro is the Physiotherapy Evidence Database and it is a free database of over 36,000 randomized trials, systematic reviews and clinical practice guidelines in physiotherapy. PEDro is produced by the Centre for Evidence-Based Physiotherapy at The George Institute for Global Health. (http://www.pedro.org.au).

\section{Inclusion criteria to select the publications}

Preliminary evaluation allowed the elimination of unnecessary publications. To be included in this review, all studies investigating effect of WBV in persons with spinal cord injury needed to comply with the following criteria: be a randomized controlled trial (RCT); in the absence of RCT's, single group experimental studies were also considered (cross-over designs); published in the English language. Studies were included if they included individuals with "spinal cord injury" who performed exercises on an OVP. Data were independently abstracted by three of the reviewers and disagreements were resolved by consensus.

\section{Exclusion criteria to select the publications}

Papers were excluded if they were:

- Replies

- Review articles

- Performed with animals

- With combined techniques

- Case report

- Others techniques

- Unpublished data

- Others databases

\begin{tabular}{|c|c|c|}
\hline Keywords & PubMed & PEDRo \\
\hline "Spinal cord injury" & 28,964 & 319 \\
\hline Physiotherapy & 151,796 & 2,916 \\
\hline "Spinal cord injury" and physiotherapy & 1,929 & 34 \\
\hline Exercises & 364,206 & 3,313 \\
\hline "Spinal cord injury" and exercises & 2000 & 11 \\
\hline "Whole body vibration" & 1,592 & 257 \\
\hline "Spinal cord injury" and "whole body vibration" & 26 & 01 \\
\hline
\end{tabular}

Table 1: Number of publications in PubMed and PEDRo databases. 
Citation: Paineiras-Domingos LL, Sá-Caputo DC, Guedes-Aguiar EO, Moreira-Marconi E, Moura-Fernandes MC, et al. (2018) Whole Body Vibration Exercises on Physiological and Hemodynamic Parameters of Spinal Cord Injury Individuals: A Systematic Review. J Spine 7: 426. doi: 10.4172/2165-7939.1000426

Page 3 of 1

\section{Level of evidence (LE) and methodological quality (MQ) of the publications}

The included studies were classified according to the National Health and Medical Research Council hierarchy of evidence [41]. Each article was assigned to a one reviewer, cross-checked by a second reviewer and where there was disagreement a third party was consulted and the issue discussed until consensus was reached.

The methodological quality (MQ) of these studies was determined by the PEDRo scale [42]. In the PEDRo scale, each item (2 up to 11) has the value of one point. The scale has a maximum score of 10 points. Publications with a score of seven or greater are considered of 'high' MQ those with five to six are 'fair' quality and a score of four or below is classified as 'poor' quality [42].

\section{Data analysis}

Data were not comparable and the statistical analysis was not performed. The results of the findings of this review were summarized in a narrative form by the (Tables 1-4).

\section{Results}

As it is shown in Table 1, considering the findings in the PubMed, the publications with:

- Spinal cord injury and physiotherapy are $1.27 \%$ of the publications with physiotherapy.

- Spinal cord injury and exercises are $0.55 \%$ of articles with exercises.
- Spinal cord injury and whole body vibration are $1.82 \%$ of the papers with whole body vibration. In the PEDRo database, the publications involving "spinal cord injury" and physiotherapy, or exercises or "whole body vibration" are $1.16 \%, 0.33 \%$ and $0.77 \%$ of the publications, respectively. Twenty-seven articles were searched with the keywords "spinal cord injury" and "whole body vibration" to be analyzed.

Figure 1 shows the PRISMA [43] flowchart and twelve publications were excluded due to two were in duplicate, two were revisions, four with animals; one was a case report, one with other technique, two with combined techniques. Fifteen articles were assessed for eligibility and included in this qualitative synthesis (Figure 1).

Table 2 shows some characteristics of the individuals and two hundred and ten individuals have participated in these investigations and the ages of the individuals varied from 20 [11,24,44-46], up to 65 years old $[47,48]$. The LE of the publications shown: two [49,50] were in the Level II; Four [11,36,44,51] were in the Level III-2; four $[23,35,45,52]$ were in the Level III-3 and five $[24,46-48,53]$ were in the Level IV according to the NHMRC 2003-2007. All these publications were considered to have a "poor" MQ in the PEDRo scale. The side alternating OVP was used in four publications $[23,50,52,53]$. The range of the frequency of the vibrations generated in the platforms varied from $10 \mathrm{~Hz}$ up to $50 \mathrm{~Hz}$; and A/PPD was $0.2 \mathrm{~mm}$ up to $5 \mathrm{~mm}$.

Considering the effects of the WBV exercise to SCI individuals in Table 3, the authors used different tools to evaluate the hemodynamic responses (main outcomes), such as improvement of the popliteal artery blood velocity [50,53] arterial resting diameter [50] increase

\begin{tabular}{|c|c|c|c|c|c|c|c|c|}
\hline References & $\begin{array}{c}\text { Individuals } \\
\text { (number, sex) }\end{array}$ & $\begin{array}{c}\text { Age } \\
\text { (years) }\end{array}$ & LE & MQ & $\begin{array}{l}\text { Device of } \\
\text { Platforms }\end{array}$ & Type of OVP & $\begin{array}{c}\text { Frequency } \\
(\mathrm{Hz})\end{array}$ & $\begin{array}{l}\text { A/PPD } \\
(\mathrm{mm})\end{array}$ \\
\hline Menéndez et al. [50] & 10 (8 men /2 women) with $\mathrm{SCl}$ & $46.3 \pm 12.9$ & II & Poor & Galileo Home, Galileo, Novotec & Alternated & 10 & PPD-5 \\
\hline Menéndez et al. [53] & $\begin{array}{c}17 \text { (12 men/ } 5 \text { women) SCl } \\
\text { (ASIA A or B) }\end{array}$ & $\begin{array}{l}49.9 \pm \\
12.5\end{array}$ & ॥ & Poor & Galileo Home, Galileo, Novotec & Alternated & 10 & PPD-5 \\
\hline Da Silva et al. [52] & $\begin{array}{c}15 \text { individuals with } \mathrm{SCl} \text { (injury } \\
\text { level beneath T3) }\end{array}$ & $46 \pm 20$ & III-3 & Poor & Galileo Advanced Novotec Medical & Alternated & 30 & A-4 \\
\hline Wuermser et al. [24] & $\begin{array}{l}4 \text { women and } 5 \text { men with } \\
\text { motor complete SCl }\end{array}$ & $20-50$ & IV & Poor & Juvent 1000 & Synchronous & 34 & - \\
\hline Bosveld \& Field-Fote [49] & $\begin{array}{l}25 \text { (20 men) with motor } \\
\text { incomplete } \mathrm{SCl}\end{array}$ & $49.7 \pm 12.5$ & II & Poor & Power Plate Northbrook IL & Synchronous & 50 & A-2 \\
\hline Yarar-Fisher et al. [36] & $\begin{array}{l}11 \text { men with SCl } 10 \text { able- } \\
\text { bodied }\end{array}$ & $\mid \begin{array}{l}49.4 \pm 6.9 \\
48.2 \pm 7.6\end{array}$ & III-2 & Poor & $\begin{array}{l}\text { WAVE }{ }^{\mathrm{TM}} \text { Wave Manufacturing Inc., } \\
\text { Whole-body Advanced Vibration } \\
\text { Exercise, Windsor, Canada }\end{array}$ & Synchronous & $30,40,50$ & PPD- 2 \\
\hline Masani et al. [46] & 7 men with chronic SCI & $20-60$ & IV & Poor & WAVE Pro Plate & Synchronous & 45 & PPD-0.6- 0.7 \\
\hline $\begin{array}{l}\text { Alizadeh-Meghrazi } \\
\text { et al. [35] }\end{array}$ & 10 men (4 with chronic SCl) & $28.8 \pm 7.7$ & III-3 & Poor & $\begin{array}{c}\text { Juvent Medical, Somerset, NJ and } \\
\text { WAVE, WAVE Manufacturing, } \\
\text { Windsor, Ontario, Canada }\end{array}$ & Synchronous & $25,35,45$ & A- $0.2,0.6,1.2$ \\
\hline $\begin{array}{l}\text { Alizadeh-Meghrazi } \\
\text { et al. [44] }\end{array}$ & $\begin{array}{l}12 \text { men (5 with chronic } \mathrm{SCl} \\
\text { and } 7 \text { without } \mathrm{SCl} \text { ) }\end{array}$ & $20-50$ & III-2 & Poor & $\begin{array}{l}\text { Juvent Medical, Somerset, NJ and } \\
\text { WAVE, WAVE Manufacturing, } \\
\text { Windsor, Ontario, Canada }\end{array}$ & Synchronous & $25,35,45$ & $\begin{array}{l}\text { A-0.6, } 1.2 \\
\text { (WAVE) }\end{array}$ \\
\hline Hadi et al. [11] & 18 men (8 with SCl) & $20-50$ & III-2 & Poor & $\begin{array}{l}\text { Juvent Medical, Somerset, NJ and } \\
\text { WAVE, WAVE Manufacturing, } \\
\text { Windsor, Ontario, Canada }\end{array}$ & Synchronous & $25,35,45$ & $\begin{array}{l}\text { A- } 0.7,1.1 \\
\text { (WAVE) }\end{array}$ \\
\hline Bernhardt et al. [45] & $\begin{array}{c}11 \text { (6 men/5 women) } \\
\mathrm{SCl}(\mathrm{T} 3 \text { to } \mathrm{T} 12)\end{array}$ & $20-50$ & III-3 & Poor & $\begin{array}{c}\text { Juvent } 1000 \\
\text { Juvent Medical Somerset }\end{array}$ & Synchronous & 34 & \\
\hline Herrero et al. [23] & 8 (6 men/2 women) with SCI & $36.1 \pm 5.0$ & III-3 & Poor & Galileo Home, Galileo, Novotec & Alternated & $10,20,30$ & PPD-5 \\
\hline Sayenko et al. [51] & 14 men (8 non-SCl and 6SCI) & $23-53$ & $\mathrm{IIII}-2$ & Poor & WAVE vertical WBV plate & Synchronous & 35 & PPD-1 \\
\hline Ness \& Field-Fote [47] & 16 (8 women/4 men) with SCI & $28-65$ & IV & Poor & Power Plate Northbrook, IL & Synchronous & 50 & PPD-2 - 4 \\
\hline Ness \& Field-Fote [48] & $\begin{array}{l}3 \text { women and } 14 \text { men } \\
\text { with motor (depending on } \\
\text { incomplete SCI) }\end{array}$ & $28-65$ & IV & Poor & Power Plate Northbrook. IL & Synchronous & 50 & PPD-2 - 4 \\
\hline
\end{tabular}

Table 2: Description of the individuals (number, sex, and age), LE, MQ, the type of platform, the frequency and the amplitude used in the oscillating/vibratory platforms used in these studies. 
Citation: Paineiras-Domingos LL, Sá-Caputo DC, Guedes-Aguiar EO, Moreira-Marconi E, Moura-Fernandes MC, et al. (2018) Whole Body Vibration Exercises on Physiological and Hemodynamic Parameters of Spinal Cord Injury Individuals: A Systematic Review. J Spine 7: 426. doi: 10.4172/2165-7939.1000426

Page 4 of 1

\begin{tabular}{|c|c|c|c|c|}
\hline References & Aim & Protocol & Findings & Conclusion \\
\hline Menéndez et al. [53] & $\begin{array}{l}\text { To analyze the acute effects } \\
\text { of isolated and simultaneous } \\
\text { application of WBV and ES on } \\
\text { popliteal artery blood velocity } \\
\text { and ST of the calf in individuals } \\
\text { with SCI. }\end{array}$ & $\begin{array}{l}\text { One familiarization session, } \\
\text { and four interventions were } \\
\text { applied in random order; WBV, } \\
\text { ES, WBV+ES. Each intervention } \\
\text { consisted of } 10 \text { sets } \times 1 \text { min ON } \\
+1 \text { min OFF. Individuals were } \\
\text { seated on their own wheelchairs } \\
\text { with their feet on the vibration } \\
\text { platform, and ES was applied on } \\
\text { the gastrocnemius muscle of the } \\
\text { both legs. }\end{array}$ & $\begin{array}{l}\text { WBV+ES produced the greatest } \\
\text { increase in MBV; } 36 \% \text { and } 42 \% \text {, } \\
\text { and PBV; } 30 \% \text { and } 36 \% \text {, during } \\
\text { the intervention. This intervention } \\
\text { produced the greatest mean } \\
\text { increases in MBV }(21 \%) \text { and } \\
\text { PBV }(19 \%) \text { during the recovery } \\
\text { period, and also produced the } \\
\text { highest increase in ST during the } \\
\text { intervention }\left(2.1^{\circ} \mathrm{C}\right) \text {. }\end{array}$ & $\begin{array}{l}\text { The simultaneous application } \\
\text { of WBV+ES seems to produce } \\
\text { a greater increase in MBV and } \\
\text { PBV on the popliteal artery and } \\
\text { ST. }\end{array}$ \\
\hline Menéndez et al. [50] & $\begin{array}{l}\text { To analyze the adaptations } \\
\text { on the popliteal artery MBV, } \\
\text { PBV, RD and BF induced by } 12 \\
\text { weeks of WBV+ES in individuals } \\
\text { with SCl. The musculoskeletal } \\
\text { effects of this therapy on the } \\
\text { gastrocnemius MT and femoral } \\
\text { neck BMD also were analyzed. }\end{array}$ & $\begin{array}{l}\mathrm{SCl} \text { individuals } \mathrm{ASIA} A \text { or } \mathrm{B} \\
\text { were randomly assigned to the } \\
\mathrm{EG}=9 \text { or the control group } \mathrm{CG}=8 \text {. } \\
\text { Each subject was assessed at } \\
\text { baseline, after } 6 \text { weeks (Post- } 6 \text { ) } \\
\text { and } 12 \text { weeks of the treatment } \\
\text { (Post-12) and } 8 \text { weeks after the } \\
\text { end of the treatment (Post-20). } \\
\text { Subjects in the EG performed } \\
3010 \text {-min sessions of WBV+ES } \\
\text { during } 12 \text { weeks. }\end{array}$ & $\begin{array}{l}\text { In the EG, RD increased } \\
\text { compared with the baseline } \\
\text { value at Post- } 6 \text {, Post-12 and } \\
\text { Post-20; BF increased compared } \\
\text { with the baseline value and } \\
\text { with CG only at Post-12 and } \\
\text { WBV+ES increased the MT } \\
\text { of the gastrocnemius. BMD of } \\
\text { both hips remained invariable } \\
\text { during the study. CG showed no } \\
\text { change. }\end{array}$ & $\begin{array}{l}\text { WBV+ES improved popliteal } \\
\text { artery BF, RD and MT after } \\
12 \text { weeks in SCl patients. } \\
\text { This increase in RD remained } \\
\text { above baseline after } 8 \text { weeks. } \\
\text { WBV+ES could be considered a } \\
\text { promising alternative to reverse } \\
\text { the musculoskeletal atrophy } \\
\text { and improve peripheral vascular } \\
\text { properties in SCl individuals. }\end{array}$ \\
\hline Wuermser et al. [24] & $\begin{array}{l}\text { To examine the effect of low- } \\
\text { magnitude WBV on bone density } \\
\text { and microstructure in women and } \\
\text { men with SCl }\end{array}$ & $\begin{array}{l}\text { Individuals stood on a low- } \\
\text { magnitude vibration late within } \\
\text { a standing frame for } 20 \text { minutes } \\
\text { per day, } 5 \text { days a week and } \\
\text { for } 6 \text { months. Bone density } \\
\text { was assessed in baseline, at } 3 \\
\text { months and } 6 \text { months while on } \\
\text { intervention and after } 6 \text { months } \\
\text { off intervention. }\end{array}$ & $\begin{array}{l}\text { Standing on the low-magnitude } \\
\text { vibration plate with a standing } \\
\text { frame was well tolerated by } \\
\text { individuals. Most individuals did } \\
\text { not show an improvement in } \\
\text { bone density or microstructure } \\
\text { after } 6 \text { months of intervention. }\end{array}$ & $\begin{array}{l}\text { Longer duration of use may } \\
\text { be necessary for to identify an } \\
\text { improvement in either bone } \\
\text { density and it is possible that } \\
\text { WBV intervention is of limited } \\
\text { benefit following chronic SCl }\end{array}$ \\
\hline Yarar-Fisher et al. [36] & $\begin{array}{l}\text { To investigate the acute effects } \\
\text { of WBV on central hemodynamic } \\
\text { responses, muscles oxygenation } \\
\text { and oxygen consumption in } \\
\text { individuals with SCl versus } \\
\text { sex, age and activity-matched } \\
\text { able-bodied individuals. And } \\
\text { assess the effect of three WBV } \\
\text { frequencies on all outcome } \\
\text { measures. }\end{array}$ & $\begin{array}{l}\text { Individuals completed three } \\
\text { WBV exercise sessions at } 30, \\
40 \text { and } 50 \mathrm{~Hz} \text {. HR, MAP, SV, } \\
\mathrm{CO}, \mathrm{VO}_{2} \text { and relative changes in } \\
\text { oxygenated, desoxigenated and } \\
\text { total heme groups were obtained } \\
\text { when } \mathrm{VO}_{2} \text { steady state was } \\
\text { achieved for: pre-WBV sitting, } \\
\text { pre-WBV standing, WBV and } \\
\text { post-WBV standing. }\end{array}$ & $\begin{array}{l}\text { Both groups demonstrated small } \\
\text { but significant increases in } \mathrm{VO}_{2} \text {, } \\
\text { deoxygenated and total heme } \\
\text { groups; but the increases were } \\
\text { larger in the } \mathrm{SCl} \text { group. No } \\
\text { frequency effect was observed. }\end{array}$ & $\begin{array}{l}\text { The WBV responses do not } \\
\text { appear sufficient to induce } \\
\text { cardiovascular benefits in the } \\
\mathrm{SCl} \text { population. WBV may } \\
\text { be helpful for individuals with } \\
\mathrm{SCl} \text { in improving lower limb } \\
\text { peripheral blood flow and coping } \\
\text { with orthostatic hypotension } \\
\text { symptoms earlier in their } \\
\text { rehabilitation programs. }\end{array}$ \\
\hline Alizadeh-Meghrazi et al. [44] & $\begin{array}{l}\text { To identify the optimal WBV } \\
\text { conditions among men with } \\
\text { chronic SCI during PS and } \\
\text { facilitate the implementation and } \\
\text { future evolution of the efficacy of } \\
\text { WBV and PS for prevention and } \\
\text { treatment of SLOP in men with } \\
\text { SCI }\end{array}$ & $\begin{array}{l}\text { The EasyStand standing } \\
\text { frame was fitted on to } 2 \\
\text { available vibration platforms. } \\
\text { Accelerometers were attached } \\
\text { to the individual's forehead, hip, } \\
\text { and ankle to measure vibration } \\
\text { propagation. The individuals } \\
\text { were exposed to all combinations } \\
\text { of posture, frequencies and } \\
\text { amplitudes. }\end{array}$ & $\begin{array}{l}\text { Variations in frequency generated } \\
\text { the most noticeable changes } \\
\text { in propagation characteristics, } \\
\text { followed by variations in knee } \\
\text { angle and amplitude. }\end{array}$ & $\begin{array}{l}\text { WBV therapy delivered with use } \\
\text { of the WAVE platform with a knee } \\
\text { angle of } 140^{\circ} \text {, plate frequency of } \\
45 \mathrm{~Hz} \text { and amplitude of } 1.2 \mathrm{~mm} \\
\text { met our a priori criteria for the } \\
\text { optimal WBV condition. }\end{array}$ \\
\hline Hadi et al. [11] & $\begin{array}{l}\text { To assess feedback from SCl } \\
\text { and non-SCI individuals on the } \\
\text { usability of PS and WBV devices } \\
\text { using a priori specified knee } \\
\text { postures, plate amplitudes and } \\
\text { frequencies. }\end{array}$ & $\begin{array}{l}\text { Individuals } \\
\text { intermittent WVB during PS } \\
\text { for } 45 \text { minutes the optimized } \\
\text { WAVE and Juvent plates. WBV } \\
\text { parameters were sequentially } \\
\text { altered every } 2 \text { minutes and } \\
\text { included parameter combinations } \\
\text { of postures of } 140,160 \text { and } 180^{\circ} \\
\text { knee extension; amplitudes of } \\
0.7 \text { and } 1.1 \mathrm{~mm} \text { and frequencies } \\
\text { of } 25,35 \text { and } 45 \mathrm{~Hz} \text {. }\end{array}$ & $\begin{array}{l}\mathrm{SCl} \text { individuals reported a } \\
\text { greater frequency of positive } \\
\text { descriptions than non-SCI } \\
\text { individuals during WBV, } \\
\text { regardless of plate, posture, } \\
\text { amplitude or frequency, with the } \\
\text { exception of } 1 \text { combination of } \\
\text { parameters. Non-SCl subject } \\
\text { reported the highest frequency } \\
\text { of negative effects with the } \\
\text { Wave plate at } 160^{\circ}, 1,1 \mathrm{~mm}, 25 \\
\text { and } 35 \mathrm{~Hz} \text {. Non-SCl individuals } \\
\text { preferred the Juvent, whereas } \\
\mathrm{SCl} \text { subject preferred the Wave } \\
\text { plate. }\end{array}$ & $\begin{array}{l}\mathrm{SCl} \text { and non-SCI individuals } \\
\text { reported differing frequencies of } \\
\text { positive and negative descriptors } \\
\text { and indicated divergent device } \\
\text { preferences. SCl individuals } \\
\text { preferred Wave plate and } \\
\text { vibration at high frequency. }\end{array}$ \\
\hline Bernhardt et al. [45] & $\begin{array}{l}\text { To determine the proportion of } \\
\text { BW borne trough the lower limbs } \\
\text { in persons with } \mathrm{SCl} \text { stood with } \\
\text { and without support in their arms. }\end{array}$ & $\begin{array}{l}\text { Vertical GRF were measured } \\
\text { in individuals stood on a low- } \\
\text { magnitude vibrating plate use a } \\
\text { standing frame tray. }\end{array}$ & $\begin{array}{l}\text { With vibration, mean GRF did } \\
\text { not significantly differ from non- } \\
\text { vibration conditions for either } \\
\text { arm positions. Oscillation of GRF } \\
\text { with vibration was significantly } \\
\text { different from no-vibration } \\
\text { conditions but similar in both arm } \\
\text { positions. }\end{array}$ & $\begin{array}{l}\text { Men and women with } \mathrm{SCl} \text { using a } \\
\text { standing frame bear the majority } \\
\text { of their weight trough their lower } \\
\text { limbs. Low-magnitude vibration } \\
\text { provided additional oscillation of } \\
\text { the load-bearing forces and was } \\
\text { proportionally similar regardless } \\
\text { of arm position. }\end{array}$ \\
\hline
\end{tabular}

Table 3: Main outcomes of hemodynamic parameters of $\mathrm{SCl}$ individuals after WBV exercise protocols. 
Citation: Paineiras-Domingos LL, Sá-Caputo DC, Guedes-Aguiar EO, Moreira-Marconi E, Moura-Fernandes MC, et al. (2018) Whole Body Vibration Exercises on Physiological and Hemodynamic Parameters of Spinal Cord Injury Individuals: A Systematic Review. J Spine 7: 426. doi: 10.4172/2165-7939.1000426

Page 5 of 1

\begin{tabular}{|c|c|c|c|c|}
\hline References & Aim & Protocol & Findings & Conclusion \\
\hline Menéndez et al. [53] & $\begin{array}{l}\text { To analyze the acute effects } \\
\text { of isolated and simultaneous } \\
\text { application of WBV and ES on } \\
\text { popliteal artery blood velocity } \\
\text { and ST of the calf in individuals } \\
\text { with SCI. }\end{array}$ & $\begin{array}{l}\text { One familiarization session, } \\
\text { and four interventions were } \\
\text { applied in random order; WBV, } \\
\text { ES, WBV+ES. Each intervention } \\
\text { consisted of } 10 \text { sets } x 1 \text { min ON } \\
+1 \text { min OFF. Individuals were } \\
\text { seated on their own wheelchairs } \\
\text { with their feet on the vibration } \\
\text { platform, and ES was applied on } \\
\text { the gastrocnemius muscle of the } \\
\text { both legs. }\end{array}$ & $\begin{array}{l}\text { WBV+ES produced the greatest } \\
\text { increase in MBV; } 36 \% \text { and } 42 \% \text {, } \\
\text { and PBV; } 30 \% \text { and } 36 \% \text {, during } \\
\text { the intervention. This intervention } \\
\text { produced the greatest mean } \\
\text { increases in MBV }(21 \%) \text { and } \\
\text { PBV }(19 \%) \text { during the recovery } \\
\text { period, and also produced the } \\
\text { highest increase in ST during the } \\
\text { intervention }\left(2.1^{\circ} \mathrm{C}\right) \text {. }\end{array}$ & $\begin{array}{l}\text { The simultaneous application } \\
\text { of WBV+ES seems to produce } \\
\text { a greater increase in MBV and } \\
\text { PBV on the popliteal artery and } \\
\text { ST. }\end{array}$ \\
\hline Menéndez et al. [50] & $\begin{array}{l}\text { To analyze the adaptations } \\
\text { on the popliteal artery MBV, } \\
\text { PBV, RD and BF induced by } 12 \\
\text { weeks of WBV+ES in individuals } \\
\text { with SCI. The musculoskeletal } \\
\text { effects of this therapy on the } \\
\text { gastrocnemius MT and femoral } \\
\text { neck BMD also were analyzed. }\end{array}$ & $\begin{array}{l}\mathrm{SCI} \text { individuals ASIA A or B } \\
\text { were randomly assigned to the } \\
\mathrm{EG}=9 \text { or the control group } \mathrm{CG}=8 \text {. } \\
\text { Each subject was assessed at } \\
\text { baseline, after } 6 \text { weeks (Post- } 6 \text { ) } \\
\text { and } 12 \text { weeks of the treatment } \\
\text { (Post-12) and } 8 \text { weeks after the } \\
\text { end of the treatment (Post-20). } \\
\text { Subjects in the EG performed } \\
3010 \text {-min sessions of WBV+ES } \\
\text { during } 12 \text { weeks. }\end{array}$ & $\begin{array}{l}\text { In the EG, RD increased } \\
\text { compared with the baseline } \\
\text { value at Post-6, Post-12 and } \\
\text { Post-20; BF increased compared } \\
\text { with the baseline value and } \\
\text { with CG only at Post-12 and } \\
\text { WBV+ES increased the MT } \\
\text { of the gastrocnemius. BMD of } \\
\text { both hips remained invariable } \\
\text { during the study. CG showed no } \\
\text { change. }\end{array}$ & $\begin{array}{l}\text { WBV+ES improved popliteal } \\
\text { artery BF, RD and MT after } \\
12 \text { weeks in SCI patients. } \\
\text { This increase in RD remained } \\
\text { above baseline after } 8 \text { weeks. } \\
\text { WBV+ES could be considered a } \\
\text { promising alternative to reverse } \\
\text { the musculoskeletal atrophy } \\
\text { and improve peripheral vascular } \\
\text { properties in SCl individuals. }\end{array}$ \\
\hline Wuermser et al. [24] & $\begin{array}{l}\text { To examine the effect of low- } \\
\text { magnitude WBV on bone density } \\
\text { and microstructure in women and } \\
\text { men with SCl }\end{array}$ & $\begin{array}{l}\text { Individuals stood on a low- } \\
\text { magnitude vibration late within } \\
\text { a standing frame for } 20 \text { minutes } \\
\text { per day, } 5 \text { days a week and } \\
\text { for } 6 \text { months. Bone density } \\
\text { was assessed in baseline, at } 3 \\
\text { months and } 6 \text { months while on } \\
\text { intervention and after } 6 \text { months } \\
\text { off intervention. }\end{array}$ & $\begin{array}{l}\text { Standing on the low-magnitude } \\
\text { vibration plate with a standing } \\
\text { frame was well tolerated by } \\
\text { individuals. Most individuals did } \\
\text { not show an improvement in } \\
\text { bone density or microstructure } \\
\text { after } 6 \text { months of intervention. }\end{array}$ & $\begin{array}{l}\text { Longer duration of use may } \\
\text { be necessary for to identify an } \\
\text { improvement in either bone } \\
\text { density and it is possible that } \\
\text { WBV intervention is of limited } \\
\text { benefit following chronic } \mathrm{SCl}\end{array}$ \\
\hline Yarar-Fisher et al. [36] & $\begin{array}{l}\text { To investigate the acute effects } \\
\text { of WBV on central hemodynamic } \\
\text { responses, muscles oxygenation } \\
\text { and oxygen consumption in } \\
\text { individuals with SCl versus } \\
\text { sex, age and activity-matched } \\
\text { able-bodied individuals. And } \\
\text { assess the effect of three WBV } \\
\text { frequencies on all outcome } \\
\text { measures. }\end{array}$ & $\begin{array}{l}\text { Individuals completed three } \\
\text { WBV exercise sessions at } 30, \\
40 \text { and } 50 \mathrm{~Hz} \text {. HR, MAP, SV, } \\
\mathrm{CO}, \mathrm{VO}_{2} \text { and relative changes in } \\
\text { oxygenated, deoxygenated and } \\
\text { total heme groups were obtained } \\
\text { when } \mathrm{VO}_{2} \text { steady state was } \\
\text { achieved for: pre-WBV sitting, } \\
\text { pre-WBV standing, WBV and } \\
\text { post-WBV standing. }\end{array}$ & $\begin{array}{l}\text { Both groups demonstrated small } \\
\text { but significant increases in } \mathrm{VO}_{2} \text {, } \\
\text { deoxygenated and total heme } \\
\text { groups; but the increases were } \\
\text { larger in the } \mathrm{SCl} \text { group. No } \\
\text { frequency effect was observed. }\end{array}$ & $\begin{array}{l}\text { The WBV responses do not } \\
\text { appear sufficient to induce } \\
\text { cardiovascular benefits in the } \\
\mathrm{SCl} \text { population. WBV may } \\
\text { be helpful for individuals with } \\
\mathrm{SCl} \text { in improving lower limb } \\
\text { peripheral blood flow and coping } \\
\text { with orthostatic hypotension } \\
\text { symptoms earlier in their } \\
\text { rehabilitation programs. }\end{array}$ \\
\hline Alizadeh-Meghrazi et al. [44] & $\begin{array}{l}\text { To identify the optimal WBV } \\
\text { conditions among men with } \\
\text { chronic SCI during PS and } \\
\text { facilitate the implementation and } \\
\text { future evolution of the efficacy of } \\
\text { WBV and PS for prevention and } \\
\text { treatment of SLOP in men with } \\
\text { SCI }\end{array}$ & $\begin{array}{l}\text { The easy stand standing } \\
\text { frame was fitted on to } 2 \\
\text { available vibration platforms. } \\
\text { Accelerometers were attached } \\
\text { to the individual's forehead, hip, } \\
\text { and ankle to measure vibration } \\
\text { propagation. The individuals } \\
\text { were exposed to all combinations } \\
\text { of posture, frequencies and } \\
\text { amplitudes. }\end{array}$ & $\begin{array}{l}\text { Variations in frequency generated } \\
\text { the most noticeable changes } \\
\text { in propagation characteristics, } \\
\text { followed by variations in knee } \\
\text { angle and amplitude. }\end{array}$ & $\begin{array}{l}\text { WBV therapy delivered with use } \\
\text { of the WAVE platform with a knee } \\
\text { angle of } 140^{\circ} \text {, plate frequency of } \\
45 \mathrm{~Hz} \text { and amplitude of } 1.2 \mathrm{~mm} \\
\text { met our a priori criteria for the } \\
\text { optimal WBV condition. }\end{array}$ \\
\hline Hadi et al. [11] & $\begin{array}{l}\text { To assess feedback from } \mathrm{SCl} \\
\text { and non-SCI individuals on the } \\
\text { usability of PS and WBV devices } \\
\text { using a priori specified knee } \\
\text { postures, plate amplitudes and } \\
\text { frequencies. }\end{array}$ & $\begin{array}{l}\text { Individuals underwent } \\
\text { intermittent WVB during PS } \\
\text { for } 45 \text { minutes the optimized } \\
\text { WAVE and Juvent plates. WBV } \\
\text { parameters were sequentially } \\
\text { altered every } 2 \text { minutes and } \\
\text { included parameter combinations } \\
\text { of postures of } 140,160 \text { and } 180^{\circ} \\
\text { knee extension; amplitudes of } \\
0.7 \text { and } 1.1 \mathrm{~mm} \text { and frequencies } \\
\text { of } 25,35 \text { and } 45 \mathrm{~Hz} \text {. }\end{array}$ & $\begin{array}{l}\mathrm{SCl} \text { individuals reported a } \\
\text { greater frequency of positive } \\
\text { descriptions than non-SCI } \\
\text { individuals during WBV, } \\
\text { regardless of plate, posture, } \\
\text { amplitude or frequency, with the } \\
\text { exception of } 1 \text { combination of } \\
\text { parameters. Non-SCl subject } \\
\text { reported the highest frequency } \\
\text { of negative effects with the } \\
\text { Wave plate at } 160^{\circ}, 1,1 \mathrm{~mm}, 25 \\
\text { and } 35 \mathrm{~Hz} \text {. Non-SCl individuals } \\
\text { preferred the Juvent, whereas } \\
\mathrm{SCl} \text { subject preferred the Wave } \\
\text { plate. }\end{array}$ & $\begin{array}{l}\mathrm{SCl} \text { and non-SCI individuals } \\
\text { reported differing frequencies of } \\
\text { positive and negative descriptors } \\
\text { and indicated divergent device } \\
\text { preferences. } \mathrm{SCl} \text { individuals } \\
\text { preferred Wave plate and } \\
\text { vibration at high frequency. }\end{array}$ \\
\hline Bernhardt et al. [45] & $\begin{array}{l}\text { To determine the proportion of } \\
\text { BW borne trough the lower limbs } \\
\text { in persons with } \mathrm{SCl} \text { stood with } \\
\text { and without support in their arms. }\end{array}$ & $\begin{array}{l}\text { Vertical GRF were measured } \\
\text { in individuals stood on a low- } \\
\text { magnitude vibrating plate use a } \\
\text { standing frame tray. }\end{array}$ & $\begin{array}{l}\text { With vibration, mean GRF did } \\
\text { not significantly differ from non- } \\
\text { vibration conditions for either } \\
\text { arm positions. Oscillation of GRF } \\
\text { with vibration was significantly } \\
\text { different from no-vibration } \\
\text { conditions but similar in both arm } \\
\text { positions. }\end{array}$ & $\begin{array}{l}\text { Men and women with } \mathrm{SCl} \text { using a } \\
\text { standing frame bear the majority } \\
\text { of their weight trough their lower } \\
\text { limbs. Low-magnitude vibration } \\
\text { provided additional oscillation of } \\
\text { the load-bearing forces and was } \\
\text { proportionally similar regardless } \\
\text { of arm position. }\end{array}$ \\
\hline
\end{tabular}

Table 4: Secondary outcomes (muscle activity, lower extremity strength, spasticity and walking function) of SCI individuals after WBV exercise protocols. 
Citation: Paineiras-Domingos LL, Sá-Caputo DC, Guedes-Aguiar EO, Moreira-Marconi E, Moura-Fernandes MC, et al. (2018) Whole Body Vibration Exercises on Physiological and Hemodynamic Parameters of Spinal Cord Injury Individuals: A Systematic Review. J Spine 7: 426. doi: 10.4172/2165-7939.1000426

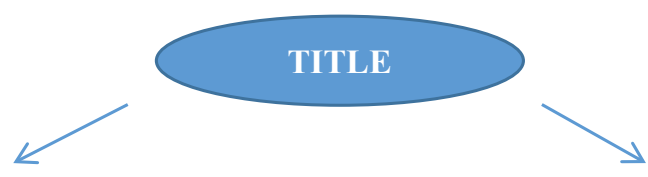

Title

Identify the report as a systematic review, meta-analysis, or both.

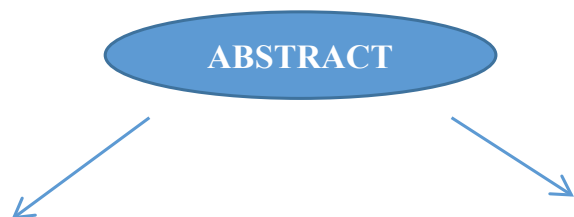

Provide a structured summary including, as applicable: background; objectives; data sources; study eligibility criteria, participants, and interventions; study appraisal and synthesis methods; results;

Structured summary

limitations; conclusions and implications of key findings; systematic review registration number.

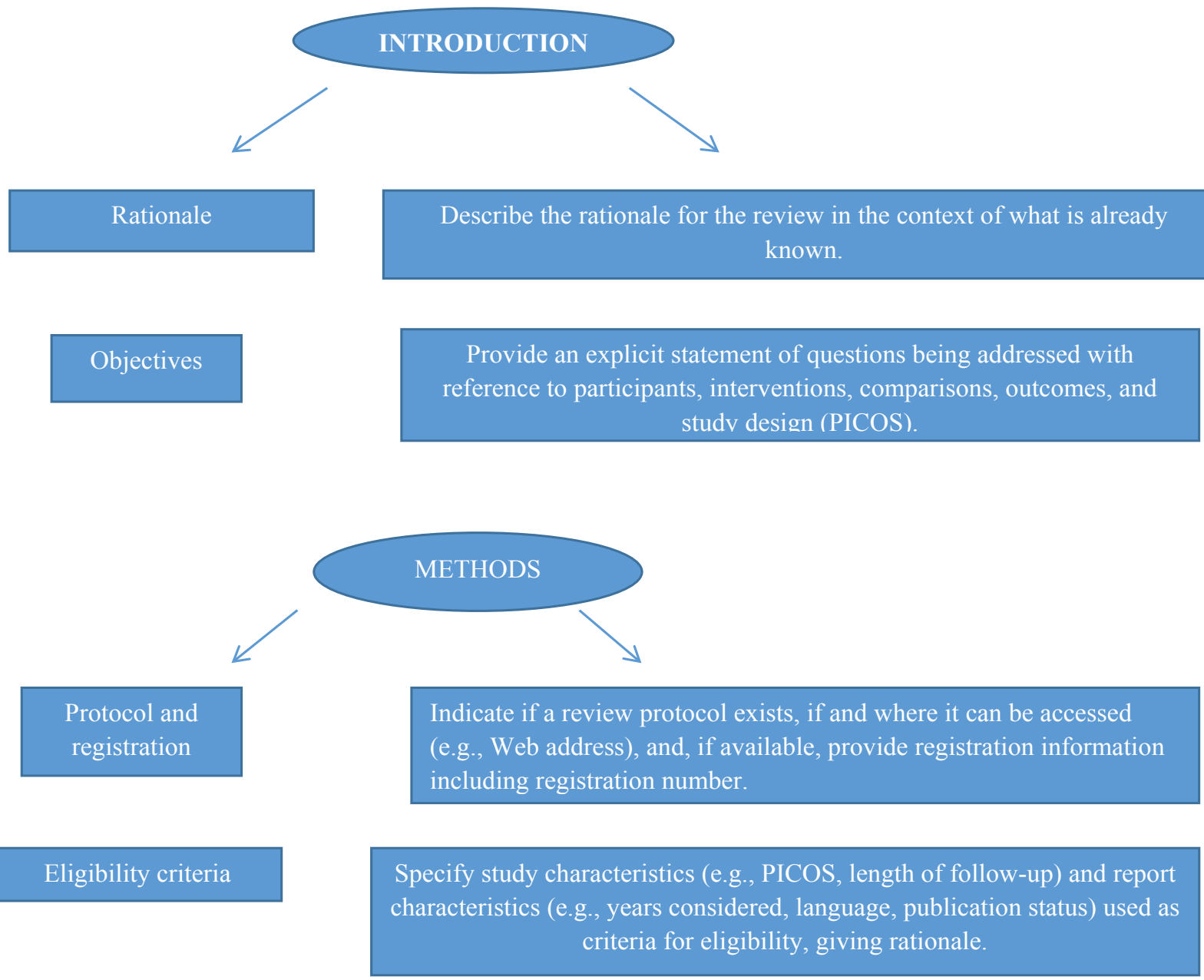


Citation: Paineiras-Domingos LL, Sá-Caputo DC, Guedes-Aguiar EO, Moreira-Marconi E, Moura-Fernandes MC, et al. (2018) Whole Body Vibration Exercises on Physiological and Hemodynamic Parameters of Spinal Cord Injury Individuals: A Systematic Review. J Spine 7: 426. doi: 10.4172/2165-7939.1000426

Information sources

Search
Describe all information sources (e.g., databases with dates of coverage, contact with study authors to identify additional studies) in the search and date last searched.

Present full electronic search strategy for at least one database, including any limits used, such that it could be repeated.
Study selection

Data collection process
State the process for selecting studies (i.e., screening, eligibility, included in systematic review, and, if applicable, included in the meta-analysis).
Describe method of data extraction from reports (e.g., piloted forms, independently, in duplicate) and any processes for obtaining and confirming data from investigators.

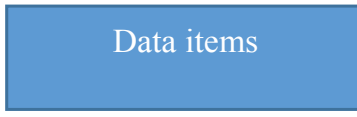

Risk of bias in individual studies

Summary measures

Synthesis of results

Risk of bias across studies
List and define all variables for which data were sought (e.g., PICOS, funding sources) and any assumptions and simplifications made.
Describe methods used for assessing risk of bias of individual studies (including specification of whether this was done at the study or outcome level), and how this information is to be used in any data synthesis.

State the principal summary measures (e.g., risk ratio, difference in means).
Describe the methods of handling data and combining results of studies, if done, including measures of consistency (e.g., $\mathrm{I}^{2}$ ) for each metaanalysis.
Specify any assessment of risk of bias that may affect the cumulative evidence (e.g., publication bias, selective reporting within studies). 
Citation: Paineiras-Domingos LL, Sá-Caputo DC, Guedes-Aguiar EO, Moreira-Marconi E, Moura-Fernandes MC, et al. (2018) Whole Body Vibration Exercises on Physiological and Hemodynamic Parameters of Spinal Cord Injury Individuals: A Systematic Review. J Spine 7: 426. doi: 10.4172/2165-7939.1000426

Additional analyses
Describe methods of additional analyses (e.g., sensitivity or subgroup analyses, meta-regression), if done, indicating which were prespecified.
Study Selection

Study characteristics

Risk of bias within studies

Results of individual studies

Synthesis of results

Risk of bias across studies

Additional analysis
Give numbers of studies screened, assessed for eligibility, and included in the review, with reasons for exclusions at each stage, ideally with a flow diagram.

For each study, present characteristics for which data were extracted (e.g., study size, PICOS, follow-up period) and provide the citations.

Present data on risk of bias of each study and, if available, any outcome level assessment (see item 12).

For all outcomes considered (benefits or harms), present, for each study: (a) simple summary data for each intervention group (b) effect estimates and confidence intervals, ideally with a forest plot.

Present results of each meta-analysis done, including confidence intervals and measures of consistency.

Present results of any assessment of risk of bias across studies (see Item 15).

Give results of additional analyses, if done (e.g., sensitivity or subgroup analyses, meta-regression [see Item 16]). 


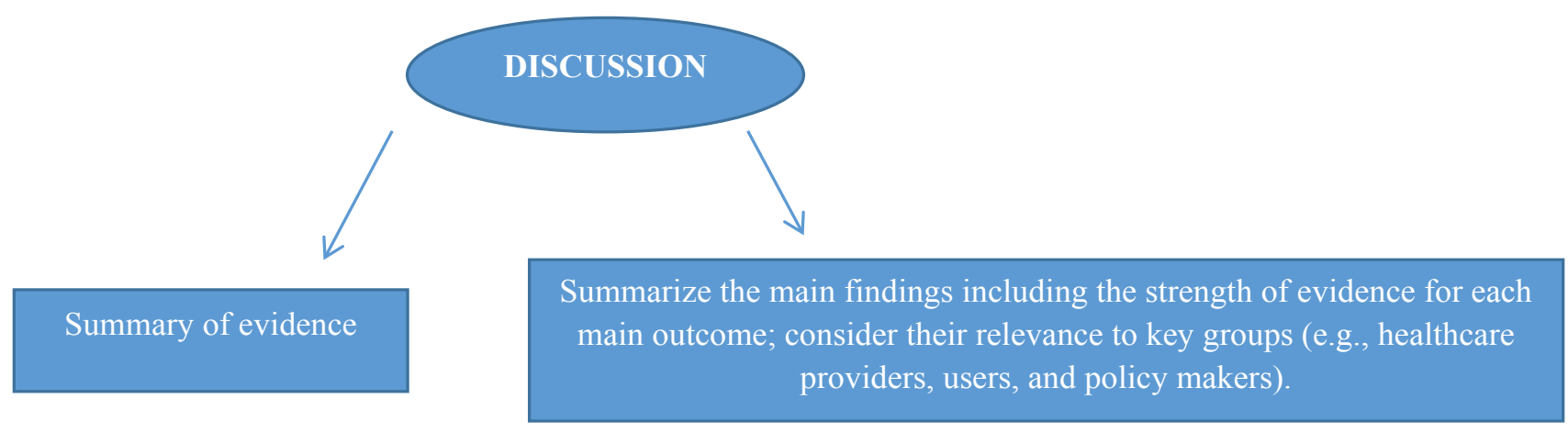

Provide a general interpretation of the results in the context of other evidence, and implications for future research.

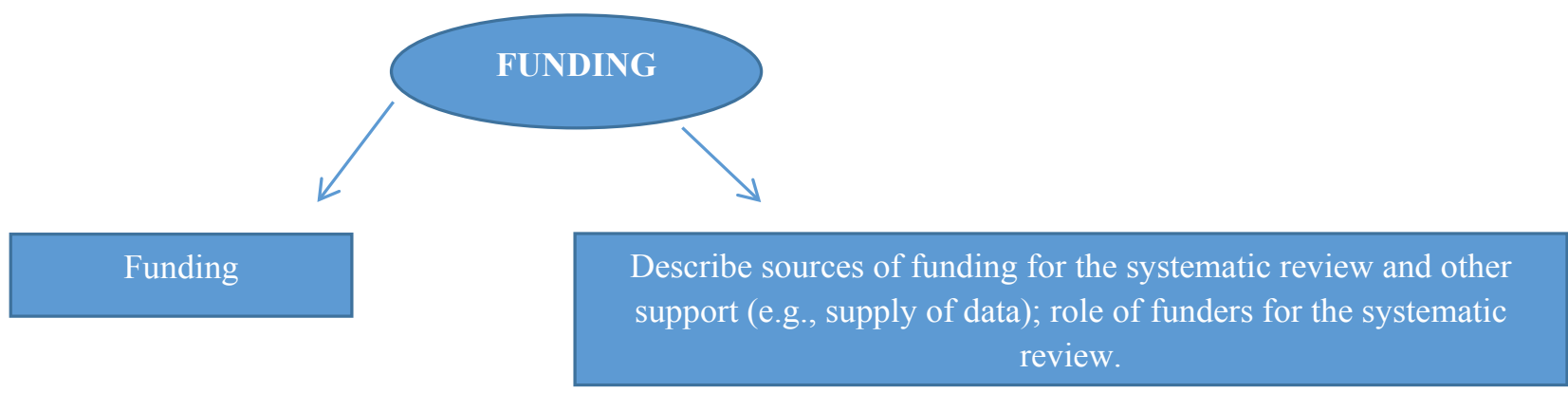

Figure 1: Flowchart indicating the steps to select the full papers analyzed in this systematic review.

of the general blood flow [36,50] muscle oxygenation and oxygen consumption 36 skin temperature [53] Also were pointed changes in the bone microstructure and prevention and treatment of sublesional osteoporosis (SLOP) [44] and the proportion of body weight (BW) borne through the lower limbs [45]. However, Wuermser and coauthors [24] show no improvement of the BMD in their used protocols. The SCI individuals were sat in wheelchair [53] or stood vibrating platform $[11,24,36,44,45,50]$. Table 4 shows some findings (related to the secondary outcomes of the current study) already described in previous reviews $[39,40]$ such as, electrophysiological activity of lower extremity muscles, lower extremity strength, quadriceps spasticity, soleus $\mathrm{H}$-reflex and walking function are presented.

\section{Discussion}

In general, little is known about which exercise interventions and which dosing schedules will promote relearning and recovery for different SCI severities [8]. In this current systematic review the hemodynamic parameters in SCI population were determined with primary results by the need for a recent investigation of the relationship between these parameters and the WBV exercises. Although the hemodynamic data is actually quite scant, for Yarar-Fisher and coauthors [36] longer duration of use the WBV plate is necessary for improvement bone density. But they observed in their studies an increased muscle oxygenation and blood flow observations in response to WBV suggest a possible application of WBV for increasing lower extremity blood flow and/or oxygen saturation in individuals with SCI. WBV exercise may be incorporated into the rehabilitation programs for reducing thrombosis susceptibility in individuals with SCI; blood pressure in individuals with SCI appeared to be maintained much better in the upright position when WBV is applied and this could be helpful in the rehabilitation of SCI patients by allowing them to avoid the difficulties of orthostatic hypotension earlier in their rehabilitation programs.

The secondary outcomes were showed in this study, have already been discussed in previous systematic reviews $[39,40]$ about the effects of WBV exercise on neuromodulation of the musculoskeletal system of individuals with SCI. Neural factors are thought to be the main contributor involved in the effects of the WBV exercise related to the increase of the physiological responses of reflex and muscle activity, and muscle function $[46,51,52]$.

Putting together the reported findings, the authors of this current revision agree with Bizzarini and coauthors [22] that are highly desirable that SCI patients begin active physical therapy programs 
Citation: Paineiras-Domingos LL, Sá-Caputo DC, Guedes-Aguiar EO, Moreira-Marconi E, Moura-Fernandes MC, et al. (2018) Whole Body Vibration Exercises on Physiological and Hemodynamic Parameters of Spinal Cord Injury Individuals: A Systematic Review. J Spine 7: 426. doi: 10.4172/2165-7939.1000426

Page 10 of 11

as soon after injury as possible. However, two important problems should be addressed when dealing with SCI patients, the reduction in cardiovascular fitness and in work capacity, by loss of sympathetic control and functional muscle mass. Moreover, for Herrero and coauthors [23] the WBV exercise responses do not appear sufficient for this, but represents an option to induce a reflex muscle contraction in individuals with difficulties or inability to evoke voluntary contractions such as SCI patients. Considering previous studies and the data pointed out by the authors selected in this revision, there is a suggestion that the WBV exercise can be a possible tool to be incorporated in rehabilitation programs of the SCI individuals.

Some scientific limitations that must be considered in the interpretation of the findings. It is necessary attention and caution should be taken when generalizing the results due to the methodological variations concerning to biomechanical parameters, type of the oscillating/vibratory platform, or the variability of the protocols used. Although the authors have tried to retrieve the articles involving WBV and SCI with the selected keywords, it is not sure that all studies on this topic have been identified, including articles that were not published in English and articles published in journals that were not indexed in the databases searched. In addition, the limited number of publications with high methodological quality (RCTs) must also be considered and this fact could of course affect the evidence of the findings. Therefore, studies with a higher methodological quality and focusing specifically on certain types of population would be desirable.

\section{Conclusion}

The increasing incidence of spinal cord injury in young and potentially active individuals who were victims of global violence, together with the increasing appearance of scientific evidence regarding the effects of WBV exercises on hemodynamic and systemic changes in the individual, were the main motivators for the construction of this review. However, further investigations with more controlled protocols related to the frequency and the amplitude/peak-to-peak displacement of the mechanical vibration, type of the OVP and groups of SCI individuals with similar ages and clinical conditions in RCT trials are recommended to determinate other hemodynamic and physiological effects of this kind of exercise in SCI individuals. Better done studies need to be done since the current research is far from conclusive.

\section{Conflict of Interest}

The authors declare that they have no conflict of interest.

\section{References}

1. Cadotte DW, Fehlings MG (2011) Spinal cord injury: A systematic review of current treatment options. Clin Orthop Relat Res 469: 732-741.

2. Sandrow-Feinberg HR, Houlé JD (2015) Exercise after spinal cord injury as an agent for neuroprotection, regeneration and rehabilitation. Brain Res 1619: $12-21$

3. Baker AB (1965) Spinal cord localization. J Lancet 85: 269-274.

4. Hadden SB (1951) Diagnosis of spinal cord disease. Med Clin North Am 35960 1765-1779.

5. Miller DH, McDonald WI, Blumhardt LD, Du Boulay GH, Halliday AM, et al. (1987) Magnetic resonance imaging in isolated non-compressive spinal cord syndromes. Ann Neurol 22: 714-723.

6. Offenbacher $\mathrm{H}$ (1992) The diagnostic impact of magnetic resonance imaging on the evaluation of suspected spinal cord disease. Wien Klin Wochenschr 104: 589.

7. Sekhon LH, Fehlings MG (2001) Epidemiology, demographics and pathophysiology of acute spinal cord injury. Spine (Phila Pa 1976) 26: S2.
8. Basso DM, Hansen CN (2011) Biological basis of exercise-based treatment: Spinal Cord Injury PMR 3: S73-77.

9. Dalyan M, Sherman A, Cardenas DD (1998) Factors associated with contractures in acute spinal cord injury. Spinal Cord 36: 405-408.

10. Lazo MG, Shirazi P, Sam M, Giobbie-Hurder A, Blacconiere MJ (2001) Osteoporosis and risk of fracture in men with spinal cord injury. Spinal Cord 39: $208-214$

11. Hadi SC, Delparte JJ, Hitzig SL, Craven BC (2012) Subjective experiences of men with and without spinal cord injury: Tolerability of the juvent and Wave whole body vibration plates. PMR 4: 954-962.

12. Andrew E (2017) Anatomy and localization of spinal cord disorders. In: Up-ToDate, Post TW (Ed), Up-To-Date, Waltham, MA. Accessed on 28 Jan 2017.

13. Devivo MJ (2012) Epidemiology of traumatic spinal cord injury: Trends and future implications. Spinal Cord 50: 365-372.

14. Hasler RM, Exadaktylos AK, Bouamra O, Benneker LM, Clancy M, et al. (2012) Epidemiology and predictor of cervical spine injury in adult major trauma patients: A multicenter cohort study. J Trauma Acute Care Surg 72: 975-981.

15. Deitrick G, Charalel J, Bauman W, Tuckman J (2007) Reduced arterial circulation to the legs in spinal cord injury as a cause of skin breakdown lesions. Angiology 58: 175-184

16. National Spinal Cord Injury Statistical Center. https://www.nscisc.uab.edu Accessed 12 Dec 2017.

17. Canadian Paraplegic Association. http://www.canparaplegic.org/en/SCI Facts_67/items/6.html. Accessed 12 Dec 2017.

18. Kirshblum SC, Burns SP, Biering-Sorensen F, Donovan W, Graves DE, et al (2011) International Standards for Neurological Classification of Spinal Cord Injury. J Spinal Cord Med 34: 535-546.

19. American Spinal Injury Association. http://asia-spinalinjury.org.

20. Spinal Cord Injury Levels \& Classification. https://www.sci-info-pages.com/ levels.html.

21. Hubli M, Gee CM, Krassioukov AV (2015) Refined assessment of blood pressure instability after spinal cord injury. Am J Hypertens 28: 173-181.

22. Bizzarini E, Saccavini M, Lipanje F, Magrin P, Malisan C, et al. (2005) Exercise prescription in individuals with spinal cord injuries. Arch Phys Med Rehabil 86 1170-1175.

23. Herrero AJ, Menéndez H, Gil L, Martín J, Martín T, et al. (2012) Effects of whole-body vibration on blood flow and neuromuscular activity in spinal cord injury. Spinal Cord 49: 554-559.

24. Wuermser LA, Beck LA, Lamb JL, Atkinson JE, Amin S, et al. (2015) The effect of low-magnitude whole body vibration on bone density and microstructure in men and women with chronic motor complete paraplegia. J Spinal Cord Med 38: 178-186.

25. Rittweger J (2010) Vibration as an exercise modality: How it may work, and what its potential might be. Eur J Appl Physiol 108: 877-904.

26. Rauch F, Sievanen H, Boonen S, Cardinale M, Degens H, et al. (2010) Reporting whole-body vibration intervention studies: Recommendations of the International Society of Musculoskeletal and Neuronal Interactions. J Musculoskelet Neuronal Interact 10: 193-198.

27. Cochrane DJ (2011) Vibration exercises: The potential benefits. Int J Sports Med 32: 75-99.

28. Morel DS, Dionello CF, Moreira-Marconi E Brandão-Sobrinho-Neto S, Paineiras-Domingos LL, et al. (2017) Relevance of whole body vibration exercise in sport: a short review with soccer, diver and combat sport. Afr J Tradit Complement Altern Med 14: 19-27.

29. Sitjà Rabert M, Rigau Comas D, Fort Vanmeerhaeghe A, Santoyo Medina $C$ Roqué i Figuls M, et al. (2012) Whole-body vibration training for patients with neurodegenerative disease. Cochrane Database Syst Rev 2: CD009097.

30. Van Nes IJ, Latour H, Schils F, Meijer R, Van Kuijk A, et al. (2006) Long-term effects of 6-week whole-body vibration on balance recovery and activities of daily living in the post-acute phase of stroke: A randomized, controlled trial. Stroke 37: 2331-2335.

31. Ahlborg L, Andersson C, Julin P (2006) Whole-body vibration training compared with resistance training: effect on spasticity, muscle strength and motor performance in adults with cerebral palsy. J Rehabil Med 38: 302-308. 
Citation: Paineiras-Domingos LL, Sá-Caputo DC, Guedes-Aguiar EO, Moreira-Marconi E, Moura-Fernandes MC, et al. (2018) Whole Body Vibration Exercises on Physiological and Hemodynamic Parameters of Spinal Cord Injury Individuals: A Systematic Review. J Spine 7: 426. doi: 10.4172/2165-7939.1000426

Page 11 of 11

32. Schuhfried O, Mittermaier C, Jovanovic T, Pieber K, Paternostro-Sluga T (2005) Effects of whole-body vibration in patients with multiple sclerosis: A pilot study. Clin Rehabil 19: 834-842.

33. Sá-Caputo DC, Dionello CF, Frederico EHFF, Paineiras-Domingos LL, SousaGonçalves CR, et al. (2017) Whole-body vibration exercise improves functional parameters in patients with osteogenesis imperfecta: A systematic review with a suitable approach. Afr J Tradit Complement Altern Med 14: 199-208.

34. Moreira-Marconi E, Sá-Caputo DC, Dionello CF, Guedes-Aguiar OE, SousaGonçalves CR, et al. (2017) Whole-body vibration exercise is well tolerated in patients with Duchenne muscular dystrophy: A systematic review. Afr J Tradit Complement Altern Med 14: 2-10

35. Alizadeh-Meghrazi M, Masani K, Zariffa J, Sayenko DG, Popovic MR, et al (2014) Effect of whole-body vibration on lower-limb EMG activity in individuals with and without spinal cord injury. J Spinal Cord Med 37: 525-536.

36. Yarar-Fisher C, Pascoe DD, Gladden LB, Quindry JC, Hudson J, et al. (2014) Acute physiological effects of whole body vibration (WBV) on central hemodynamics, muscle oxygenation and oxygen consumption in individuals with chronic spinal cord injury. Disabil Rehabil 36: 136-145.

37. Davis R, Sanborn C, Nichols D, Bazett-Jones DM (2010) The effects of whole body vibration on bone mineral density for a person with a spinal cord injury: A case study. Adapt Phys Activ Q 27: 60-72.

38. Games KE, Sefton JM (2013) Whole-body vibration influences lower extremity circulatory and neurological function. Scand J Med Sci Sports 4: 516-523.

39. Sadeghi M, Sawatzky B (2014) Effects of vibration on spasticity in individuals with spinal cord injury: a scoping systematic review. Am J Phys Med Rehabil 93: 995-1007.

40. Ji Q, He H, Zhang C, Lu C, Zheng Y, et al. (2016) Effects of whole-body vibration on neuromuscular performance in individuals with spinal cord injury: A systematic review. Clin Rehabil 31: 1279-1291.

41. NHMRC additional levels of evidence and grades for recommendations for developers of guidelines. 2013. http://www.nhmrc.gov.au/ filesnhmrc/file/ guidelines/levels grades05.pdf.

42. The PEDro scale. http://www.pedro.org.au/english/downloads/pedro-scale.

43. Liberati A, Altman D, Tetzlaff J, Mulrow C, Gøtzsche PC, et al. (2009) The PRISMA statement for reporting systematic reviews and meta-analyses of studies that evaluate health care interventions: Explanation and elaboration. $J$ Clin Epidemiol 62: e1-34.

44. Alizadeh-Meghrazi M, Masani M, Popovic MR, Craven BC (2012) Whole-body vibration during PS in individuals with spinal cord injury: Effects of Plate choice, frequency, amplitude, and subject's posture on vibration propagation PM R 4 963-975

45. Bernhardt KA, Beck LA, Lamb JL, Kaufman KR, Amin S, et al. (2012) Weight bearing through lower limbs in a standing frame with and without arm support and low-magnitude whole-body vibration in men and women with complete motor paraplegia. Am J Phys Med Rehabil 91: 300-308.

46. Masani K, Alizadeh-Meghrazi M, Sayenko DG, Zariffa J, Moore C, et al. (2014) Muscle activity, cross-sectional area, and density following PS and whole body vibration: A case series. J Spinal Cord Med 37: 575-581.

47. Ness LL, Field-Fote EC (2009a) Whole-body vibration improves walking function in individuals with spinal cord injury: a pilot study original research article. Gait Posture 30: 436-440.

48. Ness LL, Field-Fote EC (2009b) Effect of whole-body vibration on quadriceps spasticity in individuals with spastic hypertonia due to spinal cord injury. Restor Neurol Neurosci 27: 621-631.

49. Bosveld R, Field-Fote EC (2015) Single-dose effects of whole body vibration on quadriceps strength in individuals with motor-incomplete spinal cord injury. J Spinal Cord Med 38: 784-791.

50. Menéndez H, Ferrero $C$, Martín-Hernández J, Figueroa A, Marín PJ, et al (2016a) Chronic effects of simultaneous electro-myostimulation and vibration on leg blood flow in spinal cord injury. Spinal Cord 54: 1169-1175.

51. Sayenko DG, Masani K, Alizadeh-Meghrazi M, Popovic MR, Craven BC (2010) Acute effects of whole body vibration during PS on soleus $\mathrm{H}$-reflex in individuals with and without spinal cord injury. Neuroscience Letters 482: 66-70.

52. Da Silva U, Villagra HA, Oliva LL, Marconi NF (2016) EMG activity of upper limb on spinal cord injury individuals during whole-body vibration. Physiol Int 103: 361-367.

53. Menéndez $\mathrm{H}$, Ferrero $\mathrm{C}$, Martín-Hernández J, Figueroa A, Marín PJ, et al. (2016b) Acute effects of simultaneous electro-myostimulation and vibration on leg blood flow in spinal cord injury. Spinal Cord 54: 383-389. 